\title{
Vascular endothelial growth factor, matrix metalloproteinases, and cyclooxygenase- 2 influence prognosis of uterine cervical cancer in young women
}

\author{
MAIKO NORIYUKI, TOSHIYUKI SUMI, XU ZHI, FUMIKO MISUGI, HIROYUKI NOBEYAMA, \\ HIROYUKI YOSHIDA, YOSHINARI MATSUMOTO, TOMOYO YASUI, KEN-ICHI HONDA and OSAMU ISHIKO \\ Department of Obstetrics and Gynecology, Osaka City University Graduate School of Medicine, \\ 1-4-3, Asahimachi, Abeno-ku, Osaka 545-8585, Japan
}

Received April 23, 2007; Accepted June 22, 2007

\begin{abstract}
Recent changes in the lifestyle of young women have led to an increase in the rate of uterine cervical cancer. We investigated the clinicopathological characteristics of uterine cervical cancer in young women, and examined the expression of vascular endothelial growth factor (VEGF), matrix metalloproteinases (MMPs) and cyclooxygenase-2 (COX-2). Tumor samples from 439 patients with uterine cervical cancer, who were initially treated at Osaka City University Medical School Hospital, Japan between 1995 and 2004, were stained immunohistochemically. The patients were classified into two groups according to age at onset: group $\mathrm{Y}$ included women aged $\leq 35$ years, and group $\mathrm{O}$ included women aged $\geq 36$ years. Group $Y$ had more cases of squamous cell carcinoma, while group $\mathrm{O}$ had more advanced cases $(\mathrm{P}<0.05)$. Advanced cases (beyond stage $\mathrm{Ib} 2)$ had a significantly worse prognosis in group $\mathrm{Y}$ than in group $\mathrm{O}$ $(\mathrm{P}<0.05)$. There were no differences between the two groups in the expressions of VEGF, MMP-2 and COX-2. However, in advanced cases (beyond stage Ib2), the expression of VEGF, MMP-2 and COX-2 was significantly greater in group $\mathrm{Y}$ than in group $\mathrm{O}(\mathrm{P}<0.05)$. The above findings suggest that the expression of VEGF, MMPs and COX-2 is related to a worse prognosis for advanced uterine cervical cancer in young women.
\end{abstract}

\section{Introduction}

During the 1970s, uterine cervical cancer accounted for $>90 \%$ of all uterine cancer in Japan, but since 1980, its prevalence has been declining. However, the incidence of uterine cervical cancer is increasing for young women in

Correspondence to: Dr Toshiyuki Sumi, Department of Obstetrics and Gynecology, Osaka City University Graduate School of Medicine, 1-4-3, Asahimachi, Abeno-ku, Osaka 545-8585, Japan E-mail: sumi-toshi@med.osaka-cu.ac.jp

Key words: cyclooxygenase-2, matrix metalloproteinases, uterine cervical cancer, vascular endothelial growth factor their 20s and 30s, despite the fact that the average age of the Japanese population is increasing (1-3). Commonly, uterine cervical cancer advances faster in young women than in older women. However, to the best of our knowledge, there have been no studies documenting this trend.

Various processes are involved with cancer invasion and metastasis, and they can be roughly divided into the following: i) an increase in the size of the primary lesion induces interstitial fusion, vascularization and lymph duct formation; ii) cancer cells detach from the primary lesion and produce proteases that destroy the surrounding matrix and basal membrane, and invade vessels; iii) cancer cells migrate inside the vessels and then adhere to endovascular cells of a target organ, which is then invaded; and iv) cancer cells multiply and form a metastatic lesion. Previous studies have documented that various proteins are involved in these processes.

The vascular endothelial growth factor (VEGF) family is a group of specific angiogenic agents that act to increase vessel permeability, as well as endothelial cell growth, proliferation and differentiation $(4,5)$. Currently, at least six members of the VEGF family have been identified (6-12). Recent studies have shown that higher VEGF expression is correlated with poor prognosis in many human malignancies (16-23), including uterine cervical cancer (21-23).

Matrix metalloproteinases (MMPs) are thought to play a central role in stromal invasion, given their ability to penetrate the basement membrane and degrade the underlying extracellular matrix (ECM) components $(24,25)$. At least 20 different MMP family members have been identified. Elevated expression of MMP-2 and MMP-9 has been reported in several types of human cancer (26-29), including uterine cervical carcinoma $(30,31)$.

It is well known that cyclooxygenase (COX)-2, a key enzyme involved in the conversion of arachidonic acid to prostaglandins, plays a significant role in carcinogenesis, in addition to its well-established role in inflammatory reactions $(32,33)$. Several studies have shown that COX-2 is upregulated in many human malignancies (34-36), including uterine cervical cancer $(37,38)$.

Thus, our hypothesis is that these proteins are related to the differences in the clinical course between young and older patients with uterine cervical cancer. Therefore, we 
Table I. Patient characteristics.

\begin{tabular}{lcc}
\hline & Group Y & Group O \\
\hline No. of cases & 61 & 378 \\
Age $^{\text {a }}$ (years) & $31.1 \pm 3.2$ & $57.9 \pm 13.2$ \\
& $(25-35)$ & $(36-89)$ \\
Pathological types & & \\
Squamous cell carcinoma & 55 & 306 \\
Adenocarcinoma & 4 & 51 \\
Adenosquamous cell carcinoma & 1 & 7 \\
Others & 1 & 14 \\
FIGO stage & & \\
I & 47 & 161 \\
II & 5 & 78 \\
III & 6 & 102 \\
IV & 3 & 37 \\
\hline
\end{tabular}

${ }^{\mathrm{a}}$ Mean $\pm \mathrm{SD}$.

investigated the prognosis of uterine cervical cancer in young and older patients over the past 10 years. Expression of VEGF, MMP-2, MMP-7, MMP-9 and COX-2 was determined immuno-histochemically and compared between young and older patients.

\section{Materials and methods}

Patients and samples. We reviewed 439 cases of uterine cervical cancer that were initially treated at Osaka City University Medical School Hospital, Japan between 1995 and 2004 (Table I). Tumor samples were obtained from punch biopsies or from primary surgery. The patients were classified into two groups according to age at onset: group Y included women who were $\leq 35$ years of age, and group $\mathrm{O}$ included women who were $\geq 36$ years of age. The groups were compared with respect to pathological type, clinical stage, overall survival and disease-free survival. Based on the International Federation of Gynecology and Obstetrics (FIGO) criteria, the 61 group $\mathrm{Y}$ cases were classified into stage I $(n=47)$, stage II $(n=5)$, stage III $(n=6)$ and stage IV $(n=3)$, and the 378 group $O$ cases were classified into stage I $(n=161)$, stage II $(n=78)$, stage III $(n=102)$ and stage IV $(n=37)$. Clinicopathologically, the 61 group $Y$ cases were classified into squamous cell carcinoma $(n=55)$, adenocarcinoma $(n=4)$, adenosquamous cell carcinoma $(n=1)$ and others $(n=1)$, and the 378 group $O$ cases were classified into squamous cell carcinoma $(n=306)$, adenocarcinoma $(n=51)$, adenosquamous cell carcinoma $(n=7)$ and others $(n=14)$. Written informed consent was obtained from all patients prior to immunohistochemical examination.

Immunohistochemical analysis. Expression of MMP-2, MMP-7, MMP-9, VEGF and COX-2 was investigated in paraffin-embedded sections using the avidin-biotinperoxidase complex method. The paraffin sections $(5 \mu \mathrm{m}$
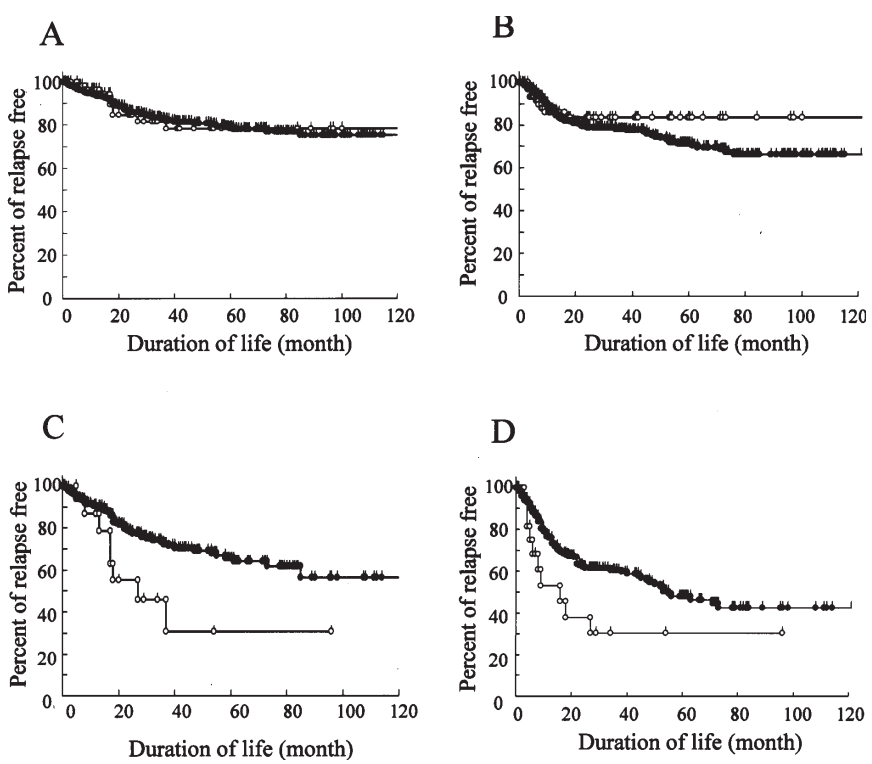

Figure 1. Survival in group Y (open circles) and group O (closed circles). There was no significant difference between the two groups (A and B). In the advanced cases beyond stage Ib2, group Y patients had significantly $(\mathrm{P}<0.05)$ worse overall and disease-free survival $(\mathrm{C}$ and $\mathrm{D})$. Kaplan-Meier and Generalized Wilcoxon calibration.

thick) were de-paraffinized and immersed in 3\% hydrogen peroxidase in methanol to block endogenous peroxidase activity. Next, an antigen retrieval procedure was performed by immersing the slides in $10 \mathrm{mM}$ citrate buffer ( $\mathrm{pH}$ 6.0) and heating in an autoclave at $121^{\circ} \mathrm{C}$ for $10 \mathrm{~min}$. After washing in PBS, the tissue sections were preblocked using $10 \%$ normal goat serum for $15 \mathrm{~min}$. The protocol for the Dako LSAB 2 peroxidase kit (Dako, Kyoto, Japan) was followed. The sections were incubated overnight with the primary antibodies in a humidity chamber at $4^{\circ} \mathrm{C}$. The primary antibodies used for this study were monoclonal mouse antihuman MMP-2, MMP-7, MMP-9 (Fuji Chemical Industries, Toyama, Japan), VEGF (Santa Cruz Biotechnology, Santa Cruz, CA) and COX-2 (IBL, Gunnma, Japan). The working dilutions for each primary antibody were 1:100 for antiMMP-2 and MMP-9, 1:50 for anti-MMP-7, 1:100 for VEGF, and 1:10 for COX-2. Sections were rinsed with PBS for $15 \mathrm{~min}$ and incubated for $1 \mathrm{~h}$ with the secondary antibody (biotinylated goat anti-mouse and rabbit immunoglobulin G secondary antibody; Dako). The sections were then incubated with streptavidin-peroxidase complex, and 3,3'diaminobenzidine was used as a chromogen. The sections were counterstained with Mayer's hematoxylin. The specificity of the immunohistochemical reactions was checked by omitting the primary antibody.

The quantitative analysis of MMP-2, MMP-7, MMP-9, VEGF and COX-2 expression was based on the scoring method of Sinicrope et al (39). The mean percentage of positive tumor cells was determined in five areas at $\mathrm{x} 400$ magnification and assigned to one of the following categories: $0,<5 \% ; 1,5-25 \% ; 2,25-50 \% ; 3,50-75 \%$; or $4,>75 \%$. The intensity of immunostaining was scored as follows: $1+$, weak; $2+$, moderate; or $3+$, intense. For each specimen, the percentage of positive tumor cells was multiplied by the staining intensity to produce a weighted score. 
A

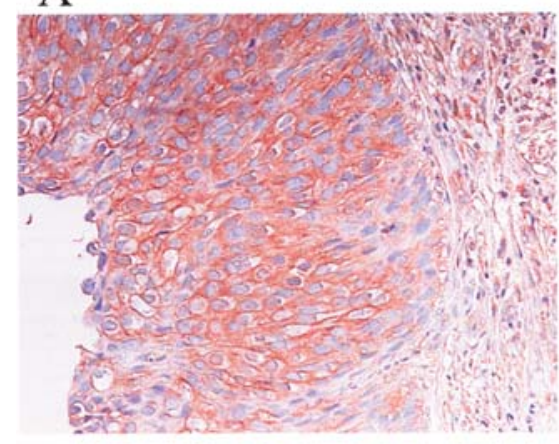

$\mathrm{C}$

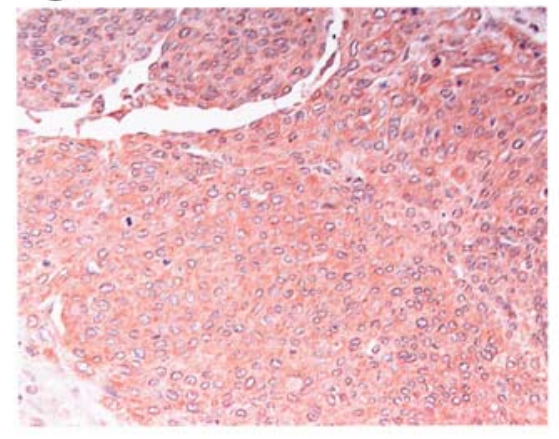

E

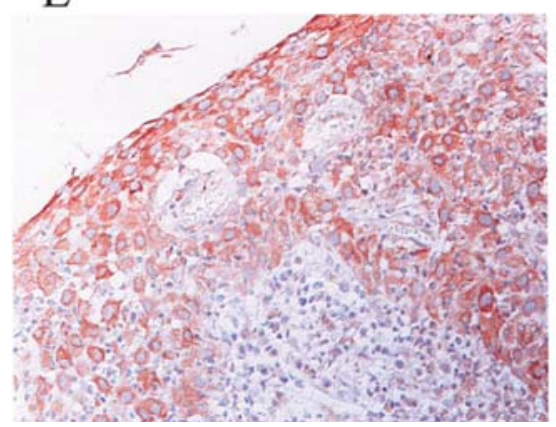

B

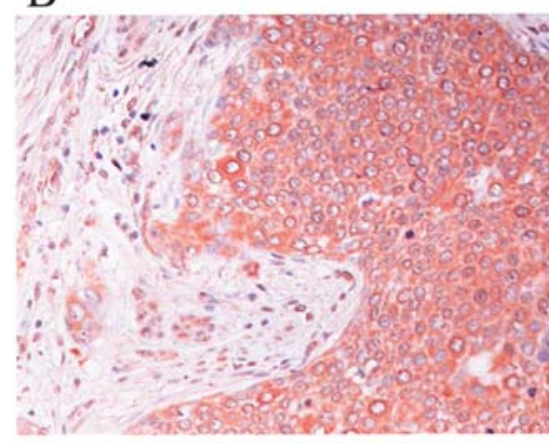

$\mathrm{D}$

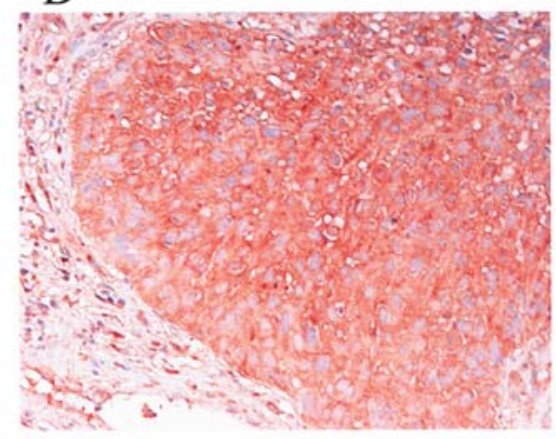

Figure 2. Immunohistochemical staining of VEGF, MMP-2, MMP-7, MMP-9 and COX-2 in uterine cervical cancer. (A) VEGF was expressed in tumor cells and in the surrounding stroma. (B-D) MMP-2, MMP-7 and MMP-9 were expressed in tumor cells and in the surrounding stroma. (E) COX-2 was expressed in tumor cells and in the surrounding stroma. Original magnification $\mathrm{x} 400$.

Statistics. For the prognostic analyses, Kaplan-Meier and Generalized Wilcoxon calibration were used. StatView 5.0 (Abacus Concepts, Berkley, CA, USA) was used for data analysis. Statistical significance was set at the 0.05 level. Continuous variables are expressed as the mean \pm standard deviation $(\mathrm{SD})$ and mean \pm standard error $(\mathrm{SE})$, as shown in the figures. The weighted scores were compared using the Mann-Whitney U test. Student's t-test was used to compare the number of invading cells between groups.

\section{Results}

Patient characteristics. The number of cases in group Y has been increasing over the 10 years from 1995 to 2004 (data not shown). The mean age of group $\mathrm{Y}$ was $31.1 \pm 3.2$ years (range, 25-35 years) and that of group O was 57.9 \pm 13.2 years (range, 36-89 years). There were significantly more cases of squamous cell carcinoma in group $\mathrm{Y}$ than in group $\mathrm{O}(\mathrm{P}<0.05)$ (Table I). There were significantly more advanced stages in group $\mathrm{O}$ than in group $\mathrm{Y}(\mathrm{P}<0.05)$ (Table I).

Survival. There was no significant difference between group $\mathrm{Y}$ and group $\mathrm{O}$ in overall and disease-free survival (Fig. 1A and B). However, group Y patients had a significantly worse overall and disease-free survival in the advanced cases beyond stage Ib2 (Fig. 1C and D).

Expression of VEGF. VEGF was expressed in the cytoplasm of tumor cells and in the surrounding stroma (Fig. 2A). Overall, there was no significant difference in VEGF expression between group $\mathrm{Y}$ and group $\mathrm{O}$ (Fig. 3A). However, in the advanced cases beyond stage Ib2, VEGF expression was significantly greater in group $\mathrm{Y}$ than in group $\mathrm{O}$ (Fig. 3B).

Expression of MMPs. MMP-2, MMP-7 and MMP-9 were expressed in the cytoplasm of tumor cells and in the surrounding stroma (Fig. 2B and D). Overall, there was no significant difference in MMP-2 expression between group $\mathrm{Y}$ and group $\mathrm{O}$ (Fig. 4A). However, in the advanced cases beyond stage Ib2, MMP-2 expression was significantly greater in group $\mathrm{Y}$ than in group O (Fig. 4B). MMP-7 

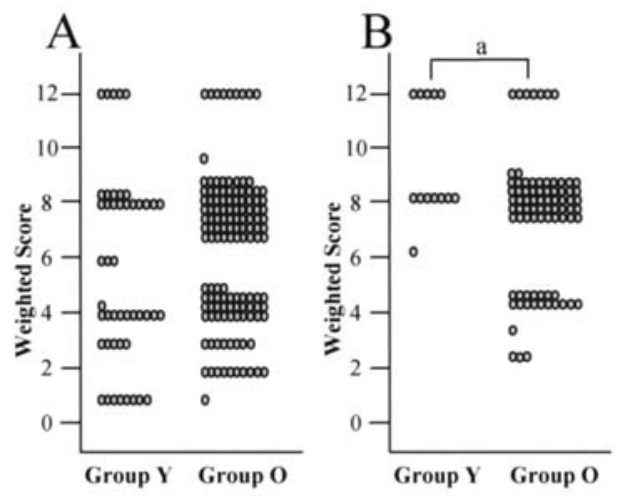

Figure 3. Weighted score of VEGF in uterine cervical cancer for all cases (A) and in the advanced cases beyond Stage Ib2 (B). (a) $\mathrm{P}<0.05$ (MannWhitney U test).
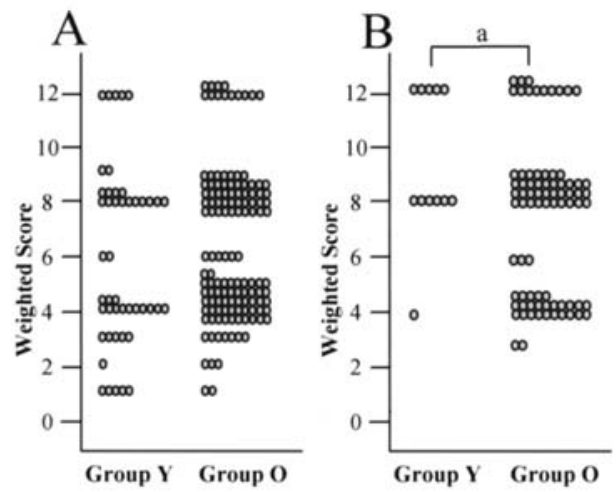

Figure 4. Weighted score of MMP-2 in uterine cervical cancer for all cases (A) and in the advanced cases beyond stage Ib2 (B). (a) $\mathrm{P}<0.05$ (MannWhitney U test).
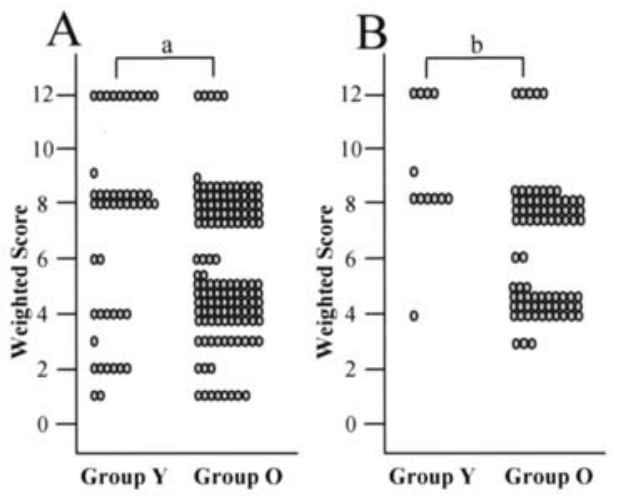

Figure 5. Weighted score of MMP-7 in uterine cervical cancer for all cases (A) and in the advanced cases beyond stage Ib2 (B). (a) $\mathrm{P}<0.05$; (b) $\mathrm{P}<0.01$ (Mann-Whitney U test).

expression was significantly greater in group $\mathrm{Y}$ than in group $\mathrm{O}$, both overall and in the advanced cases beyond stage Ib2 (Fig. 5). However, in the advanced cases beyond stage Ib2, MMP-7 expression was much greater in group Y than in group O (Fig. 5B). MMP-9 expression was significantly greater in group $\mathrm{Y}$ than in group $\mathrm{O}$, both overall and in the advanced cases beyond stage Ib2 (Fig. 6).
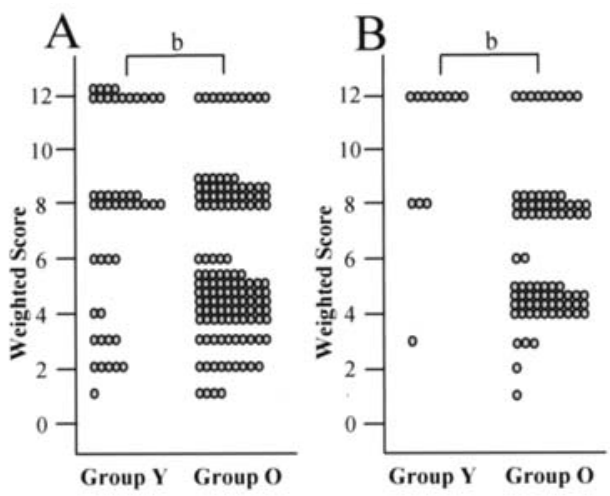

Figure 6. Weighted score of MMP-9 in uterine cervical cancer for all cases (A) and in the advanced cases beyond stage Ib2 (B). (b) $\mathrm{P}<0.01$ (MannWhitney U test).
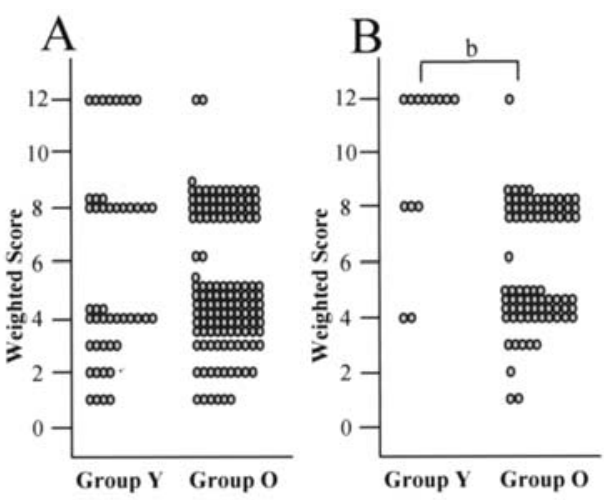

Figure 7. Weighted score of COX-2 in uterine cervical cancer for all cases (A) and in the advanced cases beyond stage Ib2 (B). (b) $\mathrm{P}<0.01$ (MannWhitney U test).

Expression of COX-2. COX-2 was expressed in the cytoplasm of tumor cells and in the surrounding stroma (Fig. 2E). Overall, there was no significant difference in COX-2 expression between group $\mathrm{Y}$ and group $\mathrm{O}$ (Fig. 7A). However, in the advanced cases beyond stage Ib2, COX-2 expression was significantly greater in group $\mathrm{Y}$ than in group O (Fig. 7B).

\section{Discussion}

While squamous cell carcinoma accounts for most uterine cancers, adenocarcinoma and adenosquamous cell carcinoma account for $\sim 15 \%$. Compared to squamous cell carcinoma, lymph node metastasis is likely to occur early in adenocarcinoma, which has a worse prognosis because it is often unresponsive to therapy $(40,41)$. In the present study, when compared to group $\mathrm{O}$, group $\mathrm{Y}$ had a significantly higher incidence of squamous cell carcinoma and early cancer (Table I). However, there was no significant difference in the overall survival between the two groups (Fig. 1A and B). Among patients with advanced cancer beyond stage Ib2, the prognosis was significantly poorer for group Y than for group $\mathrm{O}$ (Fig. 1C and D). Tumor size is also considered to be a prognostic factor for uterine cervical cancer; tumor size is part of the FIGO clinical staging system (40-42). 
Many studies have reported a correlation between tumor size and vascular invasion $(43,44)$; this suggests that vascular invasion is related to the poor prognosis in young women with advanced cancer beyond stage $\mathrm{Ib} 2$.

The VEGF family is a group of specific angiogenic agents that act to increase vessel permeability, as well as endothelial cell growth, proliferation and differentiation $(4,5)$. Recent studies have shown that higher VEGF expression is correlated with a poor prognosis in lung cancer $(13,14)$, breast cancer (15), adenocarcinoma of the gastrointestinal tract (16), hepatocellular carcinoma (17), renal cell carcinoma (18), ovarian cancer (19), endometrial carcinoma (20), and uterine cervical cancer (21-23). In our study, in the advanced cases beyond stage Ib2, VEGF expression was significantly greater in group $\mathrm{Y}$ than in group $\mathrm{O}$ (Fig. 3B). These findings suggest that VEGF expression is related to poor prognosis in young women with advanced uterine cervical cancer beyond stage Ib2.

MMPs are thought to be critical for stromal invasion and subsequent metastasis, because these proteases can degrade many ECM components and other substances $(24,25)$. Elevated expression of MMP-2 and MMP-9 has been reported in ovarian carcinoma (26), rectal cancer (27), gastric carcinoma (28), head and neck carcinoma (29), and uterine cervical cancer $(30,31)$. Elevation of MMP-7 expression has been reported in uterine endometrial carcinoma (45) and gastric carcinoma (46). In the present study, in advanced cases beyond stage Ib2, MMP-2 expression was significantly greater in group $\mathrm{Y}$ than in group $\mathrm{O}$ (Fig. 4B), and MMP-7 expression was much greater in group $\mathrm{Y}$ than in group $\mathrm{O}$ (Fig. 5B). These findings suggest that expression of MMP-2 and MMP-7 is related to the poor prognosis of young women with advanced uterine cervical cancer beyond stage Ib2. There was no significant difference in MMP-9 expression among the stages (Fig. 6), but MMP-9 expression was significantly greater in group $\mathrm{Y}$ than in group $\mathrm{O}$, and there was a significant difference in prognosis between group $\mathrm{Y}$ and group $\mathrm{O}$. These findings suggest that MMP-9 expression may be related to the poor prognosis of young women with uterine cervical cancer.

COX-2 is a key enzyme that is involved in the conversion of arachidonic acid to prostaglandins. It plays a significant role in cell-cycle regulation, inhibition of apoptosis, and pathological angiogenesis. COX-2 promotes carcinogenesis, tumor proliferation, and the spread of disease $(32,33)$. Several studies have shown that COX-2 is up-regulated in many human malignancies (34-36), including uterine cervical cancer $(37,38)$. COX-2 expression was significantly greater in group $\mathrm{Y}$ than in group $\mathrm{O}$ in those with advanced uterine cervical cancer beyond stage Ib2 (Fig. 7B). These findings suggest that COX-2 expression is related to the poor prognosis of young women with advanced uterine cervical cancer beyond stage Ib2.

The results of the present study suggest that VEGF, MMPs and COX-2 are related to the poor prognosis of young women with uterine cervical cancer. However, the mechanism by which these factors affect survival has not yet been clarified. At present, we are in the process of clarifying the mechanism and examining therapy that targets these proteins.

\section{Acknowledgements}

We would like to thank all of the urologists and gynecologists at Osaka City University Graduate School of Medicine for their support.

\section{References}

1. Values estimated by the Population-based Cancer Registry Research Group (Chairperson : Hideki Tsukuma), supported in part by a Grant-in-Aid for Cancer Research from the Ministry of Health, Labour and Welfare, Japan. Annual Report (2003).

2. Kasamatsu T and Nakamura H: Registration of gynecologic malignancy in Japan. Nippon Rinsho 62: 44-48, 2004.

3. Kashimura M, Kawagoe T, Matsuura Y and Toki N: Epidemiology of uterine cervix cancer. Nippon Rinsho 62: 57-60, 2004.

4. Vikkola T, Karkkainen M, Claesson-Welsh L and Alitalo K: Regulation of angiogenesis via vascular endothelial growth factor receptors. Cancer Res 60: 203-212, 2000.

5. Keck PJ, Hauser SD, Krivi G, et al: Vascular permeability factor, an endothelial cell mitogen related to PDGF. Science 246: 1309-1312, 1989.

6. Senger DR, Galli SJ, Dvorak AM, Perruzzi CA, Harvey VS and Dvorak HF: Tumor cells secrete a vascular permeability factor that promotes accumulation of ascites fluid. Science 219: 983-985, 1983.

7. Maglione D, Guerriero V, Viglietto AM, Delli-Bovi P and Persico MG: Isolation of a human placenta cDNA coding for a protein related to the vascular permeability factor. Proc Acad Sci USA 88: 9267-9271, 1991.

8. Olofsson B, Pajusola K, Kaipainen A, et al: Vascular endothelial growth factor B, a novel growth factor for endothelial cells. Proc Natl Acad Sci USA 93: 2576-2581, 1996.

9. Joukov V, Pajusola K, Kaipainen A, et al: A novel vascular endothelial growth factor, VEGF-C, is a ligand for the Flt4 (VEGFR-3) and KDR (VEGFR-2) receptor tyrosine kinases. EMBO J 15: 290-298, 1996.

10. Lee J, Gray A, Yuan J, Luoh SM, Avraham H and Wood WI: Vascular endothelial growth factor-related protein: a ligand and specific activator of the tyrosine kinase receptor Flt4. Proc Natl Acad Sci USA 93: 1988-1992, 1996.

11. Achen MG, Jeltsch M, Kukk E, et al: Vascular endothelial growth factor D (VEGF-D) is a ligand for the tyrosine kinases VEGF receptor 2 (Flk1) and VEGF receptor 3 (Flt4). Proc Natl Acad Sci USA 95: 548-553, 1998.

12. Meyer M, Clauss M, Lepple-Wienhues A, et al: A novel vascular endothelial growth factor encoded by Orf virus, VEGF-E, mediates angiogenesis via signalling through VEGFR-2 (KDR) but not VEGFR-1 (Flt-1) receptor tyrosine kinases. EMBO J 18: 363-374, 1999.

13. Volm M, Koomagi R, Mattern J and Stammler G: Angiogenic growth factors and their receptors in non-small cell lung carcinomas and their relationships to drug response in vitro. Anticancer Res 17: 99-103, 1997.

14. Volm M, Koomagi R and Mattern J: Prognostic value of vascular endothelial growth factor and its receptor Flt-1 in squamous cell lung cancer. Int J Cancer 74: 64-68, 1997.

15. Yoshiji H, Gomez DE, Shibuya M and Thorgeirsson UP: Expression of vascular endothelial growth factor, its receptor, and other angiogenic factors in human breast cancer. Cancer Res 56: 2013-2016, 1996.

16. Brown LF, Berse B, Jackman RW, Tognazzi K, Manseau EJ, Senger DR and Dvorak HF: Expression of vascular permeability factor (vascular endothelial growth factor) and its receptors in adenocarcinomas of the gastrointestinal tract. Cancer Res 53: 4727-4735, 1993.

17. Suzuki K, Hayashi N, Miyamoto Y, et al: Expression of vascular permeability factor/vascular endothelial growth factor in human hepatocellular carcinoma. Cancer Res 56: 3004-3009, 1996.

18. Tomisawa M, Tokunaga T, Oshika Y, et al: Expression pattern of vascular endothelial growth factor isoform is closely correlated with tumour stage and vascularisation in renal cell carcinoma. Eur J Cancer 35: 133-137, 1999.

19. Olson TA, Mohanraj D, Carson LF and Ramakrishnan S: Vascular permeability factor gene expression in normal and neoplastic human ovaries. Cancer Res 54: 276-280, 1994. 
20. Guidi AJ, Abu Jawdeh G, Tognazzi K, Dvorak HF and Brown LF: Expression of vascular permeability factor (vascular endothelial growth factor) and its receptors in endometrial carcinoma. Cancer 78: 454-460, 1996.

21. Cheng WF, Chen CA, Lee CN, Wie HF, Hsieh FJ and Hsieh CY: Vascular endothelial growth factor and prognosis of cervical carcinoma. Obstet Gynecol 96: 721-726, 2000.

22. Kodama J, Yoshinouchi M, Seki N, Hongo A, Miyagi Y and Kudo T: Angiogenesis and platelet-derived endothelial cell growth factor/thymidine phorylase expression in cervical cancer. Int J Oncol 15: 149-154, 1999.

23. Kodama J, Seki N, Tokumo K, Hongo A, Yoshinouchi M, Okuda $\mathrm{H}$ and Kudo T: Vascular endothelial growth factor is implicated in early invasion in cervical cancer. Eur J Cancer 35: 485-489, 1999.

24. Liotta LA and Kohn EC: The microenvironment of the tumorhost interface. Nature 411: 375-379, 2001.

25. Johnsen M, Lund LR, Romer J, Almholt K and Dano K: Cancer invasion and tissue remodeling: common themes in proteolytic matrix degradation. Curr Opin Cell Biol 10: 667-671, 1998.

26. Davidson B, Goldberg I, Gotlieb WH, et al: High levels of MMP-2, MMP-9, MT1-MMP and TIMP-2 mRNA correlate with poor survival in ovarian carcinoma. Clin Exp Metastasis 17: 799-808, 1999.

27. Kumar A, Collins HM, Scholefield JH and Watson SA: Increased type-IV collagenase (MMP-2 and MMP-9) activity following preoperative radiotherapy in rectal cancer. Br J Cancer 82: 960-965, 2000.

28. Nomura H, Sato H, Seiki M, Mai M and Okada Y: Expression of membrane-type matrix metalloproteinase in human gastric carcinomas. Cancer Res 55: 3263-3266, 1995.

29. Yoshizaki T, Sato H, Maruyama Y, Murono S, Furukawa M, Park CS and Seiki M: Increased expression of membrane type 1-matrix metalloproteinase in head and neck carcinoma. Cancer 79: 139-144, 1997.

30. Sheu BC, Lien HC, Ho HN, Lin HH, Chow SN, Hang SC and Hsu SM: Increased expression and activation of gelatinolytic matrix metalloproteinases is associated with the progression and recurrence of human cervical cancer. Cancer Res 63: 6537-6542, 2003.

31. Gilles C, Polette M, Piette J, Munaut C, Thompson EW, Birembaut P and Foidart JM: High level of MT-MMP expression is associated with invasiveness of cervical cancer cells. Int J Cancer 65: 209-213, 1996.

32. Smith WL, De Witt DL and Garavito RM: Cyclooxygenases: structural, cellular, and molecular biology. Annu Rev Biochem 69: $145-182,2000$

33. Williams CS, Tsujii M, Reese J, Dey SK and DuBois RN: Host cyclooxygenase- 2 modulated carcinoma growth. J Clin Invest 105: 1589-1594, 2000.

34. Elder DJ, Halton DE, Hague A and Paraskeva C: Induction of apoptotic cell death in human colorectal carcinoma cell lines by a cyclooxygenase-2 (COX-2)-selective non-steroidal anti-inflammatory drug: independence from $\mathrm{COX}-2$ protein expression. Cancer Res 3: 1679-1683, 1997.
35. Sumi T, Ishiko O, Yoshida H, Hyun Y, Nakagawa E, Hirai K, Matsumoto $Y$ and Ogita S: Expression of cyclooxygenase- 2 in ovarian mature cystic teratomas with malignant transformation. Int J Mol Med 8: 495-498, 2001.

36. Giles D, Janine S, Margaret H, Lesley-Ann M, Nigel S and Mitch D: Correlation between cyclooxygenase-2 expression and angiogenesis in human breast cancer. Cancer Res 9: 2651-2656, 2003.

37. Ryu HS, Chang KH, Yang HW, Kim MS, Kwon HC and Oh KS High cyclooxygenase-2 expression in stage 1B cervical cancer with lymph node metastasis or parametrial invasion. Gynecol Oncol 76: 320-325, 2000.

38. Kim YB, Kim GE, Cho NH, Pyo HY, Shim SJ, Chang SK, Park HC, Suh CO, Park TK and Kim BS: Overexpression of cyclooxygenase- 2 is associated with a poor prognosis in patients with carcinoma of the uterine cervix treated with radiation and concurrent chemotherapy. Cancer 95: 531-539, 2002.

39. Sinicrope FA, Ruan SB, Cleary KR, Stephens LC, Lee JJ and Levin B: bcl-2 and p53 oncoprotein expression during colorectal tumorigenesis. Cancer Res 55: 237-241, 1995.

40. Nakanishi T, Ishikawa H, Suzuki Y, Inoue T, Nakamura S and Kuzuya K: A comparison of prognoses of pathologic stage $\mathrm{Ib}$ adenocarcinoma and squamous cell carcinoma of the uterine cervix. Gynecol Oncol 79: 289-293, 2000.

41. Irie T, Kigawa J, Minagawa Y, Itamochi H, Sato S, Akeshima R and Terakawa N: Prognosis and clinicopathological characteristics of Ib-IIb adenocarcinoma of the uterine cervix in patients who have had radical hysterectomy. Eur J Surg Oncol 26: 464-467, 2000

42. Delgado G, Bundy B, Zaino R, Sevin BU, Creasman WT and Major F: Prospective surgical-pathological study of disease-free interval in patients with stage IB squamous cell carcinoma of the cervix: a Gynecologic Oncology Group Study. Gynecol Oncol 38: 352-357, 1990 .

43. Gauthier P, Gore I, Shingleton HM, Soong SJ, Orr JW Jr and Hatch KD: Identification of histopathologic risk groups in stage IB squamous cell carcinoma of the cervix. Obstet Gynecol 66: 569-574, 1985.

44. Chung CK, Nahhas WA, Zaino R, Stryker JA and Mortel R: Histologic grade and lymph node metastasis in squamous cell carcinoma of the cervix. Gynecol Oncol 12: 348-354, 1981.

45. Misugi F, Sumi T, Okamoto E et al: Expression of matrix metalloproteinases and tissue inhibitors of metalloproteinase in uterine endometrial carcinoma and a correlation between expression of matrix metalloproteinase-7 and prognosis. Int $\mathbf{J}$ Mol Med 16: 541-546, 2005.

46. Yamashita K, Azumano I, Mai M and Okada Y: Expression and tissue localization of matrix metalloproteinase-7 (matrilysin) in human gastric carcinomas. Int J Cancer 84: 470-477, 1999. 